OPEN ACCESS

Edited by: Roberto Therón,

University of Salamanca, Spain

Reviewed by:

Zhiyi Chen,

Southwest University, China

Christopher A. Was,

Kent State University, United States

*Correspondence:

Christina Koessmeier

christina.koessmeier@uni-due.de

Specialty section:

This article was submitted to

Human-Media Interaction,

a section of the journa

Frontiers in Psychology

Received: 18 May 2021 Accepted: 08 November 2021

Published: 02 December 2021

Citation:

Koessmeier $C$ and Büttner $O B$ (2021) Why Are We Distracted by Social Media? Distraction Situations and Strategies, Reasons

for Distraction, and Individual

Differences

Front. Psychol. 12:711416 doi: 10.3389/fpsyg.2021.711416

\section{Why Are We Distracted by Social Media? Distraction Situations and Strategies, Reasons for Distraction, and Individual Differences}

\author{
Christina Koessmeier* and Oliver B. Büttner \\ Economic and Consumer Psychology, Department of Computer Science and Applied Cognitive Science, University \\ of Duisburg-Essen, Duisburg, Germany
}

Social media is a major source of distraction and thus can hinder users from successfully fulfilling certain tasks by tempting them to use social media instead. However, an understanding of why users get distracted by social media is still lacking. We examine the phenomenon of social media distraction by identifying reasons for, situations of, and strategies against social media distraction. The method adopted is a quantitative online survey $(N=329)$ with a demographically diverse sample. The results reveal two reasons for social media distraction: social (e.g., staying connected and being available) and task-related distraction (e.g., not wanting to pursue a task). We find individual differences in these reasons for distraction. For social distraction, affiliation motive and fear of missing out (FoMO) are significant predictors, while for task-related distraction, self-regulatory capabilities (self-control, problematic social media use) and FoMO are significant predictors. Additionally, typical distraction situations are noninteractive situations (e.g., watching movies, facing unpleasant tasks). Strategies used to reduce distractions mostly involved reducing external distractions (e.g., silencing the device). This paper contributes to the understanding of social media use by revealing insights into social media distraction from the user perspective.

Keywords: social media, distraction, situations, strategies, individual differences, fear of missing out, self-control

\section{INTRODUCTION}

Internet and smartphones enable users to be permanently online and permanently connected (Vorderer et al., 2018). As a consequence, users can permanently be distracted by social media. Social media distraction refers to the process by which social media cues draw individuals' attention away from a task that they originally pursued (e.g., working). Due to especially mobile access to social media, distractions by social media can occur frequently. Previous studies on multitasking have consistently demonstrated negative effects of distraction on performance (Jeong and Hwang, 2016), on academic performance among students (Junco and Cotten, 2012; Giunchiglia et al., 2018) and on well-being (e.g., Brooks, 2015). By drawing away users' attention, distractions take up limited cognitive resources.

Given these negative consequences, it is important to understand users' underlying reasons for social media distraction. Understanding the reasons for social media distraction can help to 
increase users' agency to deal with unwanted social media distractions. Therefore, our major goal is to identify the reasons that underlie users' distraction by social media. Furthermore, we examine how these reasons for distraction relate to individual differences in general (e.g., self-control) and social mediaspecific traits (e.g., problematic social media use). Additionally, to fully understand the phenomenon of social media distraction, we identify typical situations in which users are distracted, and we examine which strategies people use to handle social media distractions.

\section{THE PROBLEM OF SOCIAL MEDIA DISTRACTIONS}

Because of human's limited capacity to process information (Pashler, 1994; Lang, 2000), distraction is problematic. Thus, in order to fulfill specific tasks successfully, social media distractions should be minimized. Distractions are caused by taskirrelevant stimuli that interrupt goal-directed behavior (Clapp and Gazzaley, 2012). Such distractions should be ignored when people want to focus on a task that requires their undivided attention to fulfill a certain goal. For instance, when writing a paper or talking to someone, social media cues-as the irrelevant distractors in that situation-are distracting by drawing the attention away from the primary task.

We refer to social media distraction as the phenomenon of social media cues (the distractors) drawing the attention away from the task at hand and directing it instead toward social media. These cues can be external or internal (Wilmer et al., 2017). For instance, social media distraction can be external (i.e., from the environment), such as receiving a notification, or internal (i.e., from within a person), for example when a user starts thinking about social media (e.g., unanswered messages). While users are engaged in a task, mind wandering may lead to internal distraction (McVay and Kane, 2010). For instance, prior work showed that students' mind frequently wandered to social media when learning online (Hollis and Was, 2016). Mind wandering has been attributed to failed attentional control (McVay and Kane, 2010).

When faced with internal or external social media distractions, users can determine how to react and handle the distraction. There are three possible reactions to social media distractions: (a) ignoring the distraction and going on with the task; (b) stopping the task to use social media instead; or (c) starting to multitask (frequent switching between the task and social media). Social media cues distract from a task and offer the option of using social media. Starting to use social media as a reaction to distraction can have various reasons and how users handle this distraction can differ. The consequence of distraction can be that users start using social media (b or c). One explanation for why users engage in social media instead of ignoring it when engaged in a task, may be a failure of self-control. Research has found that social media self-control failure is related to high social media use (Du et al., 2018, p. 68). Moreover, users may engage in social media use after getting distracted in order to procrastinate. Research has indicated that procrastination-"voluntarily delay an intended course of action despite expecting to be worse off for the delay" (Steel, 2007, p. 66)-is related to high social media use (Reinecke et al., 2018; Rozgonjuk et al., 2018). The distraction may offer users an option to procrastinate instead of working on their tasks. Concluding, a user's reaction to distractions may be influenced by, for instance, a failure to control one's social media use or by the desire to procrastinate.

\section{Situations Prone to and Strategies Against Social Media Distractions}

Prior studies have usually focused on social media as a distraction in one specific situation. For instance, a review found that students frequently use social media while in a lecture, reading, or studying (Chen and Yan, 2016). Additionally, prior research has examined distractions while working (Brooks and Califf, 2017) or while actively participating in traffic (Gliklich et al., 2016). Moreover, previous research has investigated such effects in social situations, such as relationship formation (Przybylski and Weinstein, 2013) or romantic relationships (Roberts and David, 2016). To summarize, most previous studies have focused on one specific situation in which distraction is examined, but an overview of typical distraction situations is lacking in prior research. Therefore, the present study investigates which distraction situations are typical in users' daily lives.

Different strategies may be needed to successfully handle social media distraction, but so far it is unclear which strategies individuals already use. For instance, previous research has argued that closing social media tabs in the browser, turning off notifications, and trying to put the device out of sight might reduce distractions (Carrier et al., 2015; Kushlev et al., 2016). To empower social media users to avoid distractions, it is first necessary to understand the strategies that people use. Therefore, we investigate which strategies are used most frequently. In summary, we seek to identify distraction situations and strategies (RQ1).

\section{Reasons for Social Media Distraction}

Social media's strong pull factor-others have described it as "hedonic appeal" (Brooks, 2015, p. 26) or temptation (Hofmann et al., 2017)-makes users "drawn to distraction" (Aagaard, 2015, p. 93) and leads them to override their primary goals and tasks. This strong pull of social media has a high potential for distraction. For instance, research has found that students cannot focus for long on a task such as studying, and that, on average, they switch to social media after about six minutes of focused work (Rosen et al., 2013) and react to notifications shortly after their arrival (Pielot et al., 2014). In order to limit these distractions so that goals can be successfully accomplished, it is necessary to understand the underlying reasons for the distractions.

According to the uses and gratifications (U\&G) approach (Katz et al., 1974), users actively seek media to fulfill certain needs and gratifications. From a variety of media choices, users select those that they expect to fulfill their needs. Social and psychological factors as well as the context influence media use and effects (Rubin, 2002). Accordingly, we argue that social media 
distraction represents a user's active choice to fulfill certain needs. Even though external distractions can occur uncontrolled, it is a user's active choice how to handle these distractions. Similarly, users working on a task might be "hijacked by task-unrelated thought[s]" that may distract internally (McVay and Kane, 2010, p. 324). Relatedly, prior work indicated that being preoccupied with the online world increased mind wandering (Johannes et al., 2018a). Even though these internal distractions represent an attentional control failure, users can still choose how to handle such a brief moment of uncontrolled attention (i.e., how to react to an uncontrolled thought about social media that arises), similarly to a user's choice of how to handle external distractions. Users can choose whether to give in to the distraction (and start using social media) or to ignore the distraction.

In light of U\&G, we propose that a user's susceptibility to social media distractions in a specific moment represents need satisfaction (e.g., to find out whether someone texted), even though this might conflict with the user's current goalrelevant task. Users' momentary needs might influence how susceptible they are to distractions since users' needs may influence attentional control. This may result in mind wandering (internal distractions) or, for instance, looking at the smartphone (external distractions). Hence, we argue that user's needs may influence how susceptible users are to distractions. Moreover, U\&G has been widely used in previous research to investigate why people use media (Ruggiero, 2000). Similarly, we want to investigate why users get distracted by social media-that is, we are interested in the reasons for social media distraction.

Previous research has identified several motivations for using social media in general, such as to communicate (Whiting and Williams, 2013), to stay in touch (Papacharissi and Mendelson, 2010), to feel connected to others (Quan-Haase and Young, 2010), to escape (Papacharissi and Mendelson, 2010), or to pass time (Whiting and Williams, 2013). These motivations for social media use describe the overall reasons for signing up to and using social media. The present research, by contrast, focuses on the reasons for social media distraction. We examine the underlying motivation for users' increased susceptibility toward social media cues that draw the attention away from a task to which an individual originally attended. Motivations for social media use and reasons for distraction may overlap to a certain degree, but nevertheless reflect different aspects. For instance, most people do not sign up at a social media platform with the intention to procrastinate on their homework.

From a U\&G perspective, it is relevant to examine the reasons for social media distraction. As Rubin (2002) argued, "to explain media effects, we must first understand the characteristics, motivations, selectivity, and involvement" (p. 526), because these can "have important implications for media effects" (p. 536). For example, research has found that users' motivation influences which social media features they use (Smock et al., 2011). Therefore, understanding the reasons for social media distraction is a first step that enables future research to investigate the possible influences of distraction on different behaviors. Hence, this study investigates why users react to rather than ignore distracting social media cues when they are working on a task. Our second research question seeks to identify users' reasons for distraction by social media (RQ2). In particular, we are exploring which different types of social media distraction exist.

\section{Individual Differences and Social Media Distraction}

According to U\&G, individual differences influence media use and effects (Rubin, 2002; Sherry and Boyan, 2008). Similarly, we expect that users' traits contribute to individual differences in social media distraction. Based on the current literature, we identified a set of traits that we considered relevant for explaining why users are distracted by social media: basic motives, selfcontrol, impulsivity, problematic social media use, and fear of missing out (FoMO). Our rationale was to include general traits, which are not exclusively related to social media, as well as traits that are specific to social media use. Given that we did not know in advance which factors of reasons for distraction by social media would emerge from the analysis, we could not formulate specific hypotheses regarding which of the trait variables correlated with which type of distraction. Therefore, we adopted an exploratory approach. Our third research question investigates how individual differences influence the reasons for social media distraction (RQ3).

We included basic motives to address general individual differences in motivations that underlie behavior. Motives refer to stable "predisposition[s] to approach a particular class of incentives... or to avoid a particular class of threats" (Trash et al., 2012, p. 141). Previous research has identified achievement, power, and affiliation/intimacy as basic motives (Emmons, 1997; Schönbrodt and Gerstenberg, 2012). Achievement refers to striving for adherence to excellence and mastering challenging tasks. Power describes the endeavor to impact others (regarding their attitudes or behaviors) and being concerned about status and prestige. Affiliation refers to the wish to have social relations, while intimacy refers to the motive of having strong social interactions and being close to others. For instance, research has shown that, of these motives, power and affiliation are related to a positive attitude toward social media (Sariyska et al., 2019). We included these explicit motives because they represent overarching motivations for users' behavior.

Self-control and impulsivity are indicators of users' selfregulatory abilities. Self-regulation-inhibiting or overriding impulses and temptations in order to achieve a higher-level goal (Baumeister and Heatherton, 1996)-is necessary for the ability to resist the temptation of social media distractions. Previous literature has discussed self-control as a predictor for media use (Reinecke and Hofmann, 2016; Hofmann et al., 2017), demonstrating that low self-control and high impulsivity relate to higher multitasking (Wang et al., 2012; Sanbonmatsu et al., 2013) or to a fast response to messages (Berger et al., 2018).

Fear of missing out refers to the FoMO on rewarding experiences others might have (Przybylski et al., 2013). Previous research has found that it is important for people to stay socially connected (Przybylski et al., 2013). In particular, FoMO is related to higher social media use (Przybylski et al., 2013), especially in situations when pursuing a task such as studying (Milyavskaya et al., 2018). Users might show an 
increased susceptibility to social media distraction to avoid the feeling of missing out.

Problematic social media use might also influence social media distraction. In its extreme form as social media addiction, it is characterized by a preoccupation with social media, loss of control and problems in social interactions (Wegmann et al., 2017), and low self-control (Wegmann et al., 2015). This suggests that users with a tendency toward social media addiction are also more susceptible to social media distraction.

\section{Overview of the Study}

This study used an exploratory approach to address the three research questions. We explored social media distraction, in particular investigating in which situations people are most likely to be distracted and which strategies they use to regulate their distraction (RQ1). Second, we wanted to identify the reasons for social media distraction-that is, we investigated why people get distracted by social media (RQ2). Finally, we investigated if social media distraction depends on individual differences (RQ3) in trait variables (general motives, selfcontrol, impulsivity) and social media-specific variables (FoMO, problematic social media use).

Our methodological approach consisted of two steps: First, in preliminary studies, we conducted qualitative interviews to uncover users' reasons for distraction, distraction situations, and strategies, which we then pre-tested as items in followup studies. Second, for our main study and the focus of this paper, we conducted a quantitative online survey with a large and heterogeneous sample. Data and supplementary material are available via the Open Science Framework (OSF): https://osf.io/ 5pvj6/.

\section{MATERIALS AND METHODS}

\section{Preliminary Studies}

The goal of the preliminary studies was to develop the items for the research focus (reasons for distraction, distraction situations, and strategies) used in the main study. In 15 semi-structured qualitative interviews (each with a duration of 15-20 min), we asked students questions relating to why they get distracted, in which situations this was most likely to happen, and what strategies they used to limit their distraction. We asked students since we assumed these are particularly prone to distraction. Five interviews each focused on one of the three topics (reasons for social media distraction, situations for social media distraction, strategies to reduce distraction). Questions started openly but included targeted questions to find out more about the three topics. Subsequently, we developed the items based on the insights gained from the interviews; namely, we extracted and aggregated the main reasons, situations, and strategies that interviewees pointed out and we refined these based on the literature. We developed these items without any potential underlying factors in mind. We then pre-tested and refined the items in two questionnaire studies $\left(N_{1}=92 ; N_{2}=127\right)$ before including them in the main study to get a first impression of social media distractions and our items. This preliminary work resulted in the scales for reasons for distraction, distraction situations, and strategies used to limit distraction, which we then used and explored in the main study (see Measures section for a detailed description and Tables 3-5 for the items). Further information on the preliminary material is available online in our OSF repository.

\section{Main Study}

The main study was a quantitative survey. To begin, the survey asked about social media use and social media distraction in general. The survey then focused on reasons for social media distraction, potential distraction situations, and strategies used to limit distractions. The survey looked into individual differences regarding FoMO, problematic social media use, explicit motives, self-control, and impulsivity. Lastly, the survey included socio-demographic variables. The study was approved by the department's ethics committee.

\section{Sample}

For the survey, we recruited social media users via an online access panel in Germany. The prerequisites for participation in the study were having at least one social media account and using social media at least once per week. Since the aim of our study was to investigate social media distraction, it is necessary that only those people participate that are familiar with social media. In order to reach a sample reflecting a broad selection of social media users, we recruited participants aged between 18 and 69 years. $^{1}$ Overall, 382 social media users from Germany participated in the study ${ }^{2}$. To ensure data quality, we excluded 53 participants from the analysis. Of those, 10 users were excluded for interrupting survey completion. We excluded the fastest and slowest 5\% (40 respondents) to control for people not filling out the survey with attention. Three participants were excluded because of inappropriate responses to open questions. Table 1 summarizes the socio-demographic details of the participants in our final data set used for the analysis.

\section{Measures $^{3}$}

For descriptive purposes, we assessed frequency of social media use (a few times a day, daily, a few times a week, once a week, once a month or less), social media use in hours per day ("How many hours do you use social media in a regular day? I use social media for... hours per day"), and for which social media platforms participants held an account. We assessed different facets of social media distraction with three single items: (1) degree of distraction ( 1 = not much distracted by social

\footnotetext{
${ }^{1}$ We used a stratified sampling approach with specified subgroups regarding age (18-29; 30-39; 40-49; 50-59; and 60-69); at least 50 people were in each age group and there was a roughly equal gender distribution. We used this approach to ensure that the sample is demographically diverse and to avoid an unbalanced sample (e.g., younger persons might be more prone to participate in a study on social media).

${ }^{2}$ In line with the recommendation by Stevens (2009), we collected data on more than 300 people, which allowed us to focus on factor loadings of 0.4 or greater in our EFA.

${ }^{3}$ Measures are reported in order of appearance in the questionnaire. For exploratory purposes, we also assessed social media usage motivation and workrelated self-efficacy. These are not further investigated here since a discussion exceeds the scope of this paper.
} 
TABLE 1 | Socio-demographic details on sample.

\begin{tabular}{|c|c|c|c|}
\hline & $N$ & $\%$ of Sample & $M$ (SD) \\
\hline Age & & & $42.58(14.75)$ \\
\hline \multicolumn{4}{|l|}{ Gender } \\
\hline Female & 168 & 51 & \\
\hline Male & 161 & 49 & \\
\hline \multicolumn{4}{|l|}{ Education } \\
\hline Not graduated from school & 3 & 0.9 & \\
\hline Lower secondary school graduate & 25 & 7.6 & \\
\hline Secondary school certificate & 63 & 19.1 & \\
\hline Traineeship & 73 & 22.2 & \\
\hline Higher education entrance qualification & 91 & 27.7 & \\
\hline Bachelor (University degree) & 23 & 7.0 & \\
\hline Master (University degree) & 44 & 13.4 & \\
\hline Other & 7 & 2.1 & \\
\hline \multicolumn{4}{|l|}{ Occupation } \\
\hline Student (School) & 2 & 0.6 & \\
\hline Student (University) & 33 & 10.0 & \\
\hline In traineeship & 8 & 2.4 & \\
\hline Employee & 164 & 49.8 & \\
\hline Self-employed & 21 & 6.4 & \\
\hline Homemaker & 17 & 5.2 & \\
\hline Unemployed & 15 & 4.6 & \\
\hline Retired & 54 & 16.4 & \\
\hline Other & 15 & 4.6 & \\
\hline \multicolumn{4}{|l|}{ Marital status } \\
\hline Single & 91 & 27.7 & \\
\hline In a relationship & 80 & 24.3 & \\
\hline Married & 126 & 38.3 & \\
\hline Divorced & 27 & 8.2 & \\
\hline Widowed & 5 & 1.5 & \\
\hline
\end{tabular}

$N=329$.

media; 5 = very much distracted); (2) reactivity to distraction ( 1 = typically directly respond to notifications; 5 = rather take some time to react to a notification); and (3) typical source of distraction ( 1 = internally-thinking about social media-related content; 5 = externally-receiving notifications). Evaluation of distraction measured how far participants perceive their social media distraction as problematic (Table 2; five items, scaled 1$5, \alpha=0.91)$. Notification settings assessed whether participants receive all, some, or no notifications, or never stay logged in.

To find typical situations of social media distraction, participants rated 10 situations based on how often they perceived social media distraction in these situations (Table 3), ranging from (1) never/rarely to (5) very often. This scale measured the extent to which people perceived themselves as being typically distracted in certain situations. Moreover, to assess reasons for social media distraction (Table 5), participants rated each of the 16 reasons by determining how much the reason related to their distraction behavior. Participants had to think back to the previously mentioned distraction situations, complete the sentence "I get distracted in these situations, because ...," and rate each listed reason on a five-point rating scale ranging from (1) totally disagree to (5) totally agree. In order to discover people's most common strategies to limit social media distraction, the survey asked participants to indicate which strategies they already used to reduce social media distraction. Participants rated, from (1) never to (5) always, how often they would use each of these 15 strategies (Table 4). Additionally, participants rated their evaluation of strategies used (Table 2, four items, scaled 1-5, $\alpha=0.96$ ) to reduce distractions.

Problematic social media use was measured with the Internet addiction scale modified for social networking sites (s-IAT-SNS; Wegmann et al., 2015), with the two dimensions loss of control ( ix items, $\alpha=0.89$ ) and craving (six items, $\alpha=0.91$ ), rated on a five-point rating scale ranging from (1) never to (5) very often. FoMO (Przybylski et al., 2013) was measured with the revised FoMO scale (Wegmann et al., 2017), assessing online (seven items, $\alpha=0.86$ ) and offline (five items, $\alpha=0.90$ ) FoMO on a five-point rating scale ranging from (1) totally disagree to (5) totally agree.

We measured basic explicit motives-achievement $(\alpha=0.88)$, power $(\alpha=0.86)$, affiliation $(\alpha=0.81)$, and intimacy $(\alpha=0.80)$ with the Unified Motivations Scale (UMS-6; Schönbrodt and Gerstenberg, 2012), using six items for each motive. We measured self-control using the German version of the Brief SelfControl Scale (Tangney et al., 2004; Bertrams and Dickhäuser, 2009; $\alpha=0.84$ ). We assessed impulsivity with the short form of the Barratt Impulsiveness Scale (BIS-15) in German (Meule et al., 2011; $\alpha=0.81)$.

\section{RESULTS}

\section{Descriptive Summary of Social Media Use and Distraction}

Participants estimated using social media on average $2.2 \mathrm{~h}$ per day $(\mathrm{SD}=2.3)$. The most frequently used social media platform ${ }^{4}$ was WhatsApp (86\%), followed by Facebook (82\%), YouTube (67\%), Facebook Messenger (49\%), and Instagram (39\%). Half of the participants $(51 \%)$ reported having some notifications from social media activated, whereas $28 \%$ received all possible notifications, and $9 \%$ reported disabling all notifications.

Table 2 shows how participants perceived their distraction by social media. However, they reported that they experienced their distraction as rather negative. Participants stated that they generally took some time to respond to notifications instead of immediately reacting to them. The source of distraction seemed to be external rather than internal, that is, from notifications rather than from starting to think about social media.

\section{Situations and Strategies Against Social Media Distraction}

First, we identified situations and strategies (RQ1). Situations typical for social media distraction are presented in Table 3. The situations in which people reported getting distracted most often were while watching movies/series, when trying to avoid

${ }^{4}$ We used a broad definition of social media, including social networking sites and instant messaging apps. 
TABLE 2 | Descriptive measures on distraction by social media.

\begin{tabular}{lll}
\hline & M & SD \\
\hline Degree of distraction & 2.50 & 1.20 \\
Source of distraction & 2.91 & 1.28 \\
Reactivity to distraction & 3.29 & 1.07 \\
Evaluation of distraction behavior & 3.07 & 1.03 \\
Unproblematic (1)-very problematic (5) & 2.94 & 1.21 \\
Not stressful (1)-very stressful (5) & 2.82 & 1.20 \\
Not disturbing (1)-very disturbing (5) & 3.09 & 1.23 \\
Not much (1)-very much time-consuming (5) & 3.45 & 1.15 \\
Not critical (1)-very critical (5) & 3.05 & 1.19 \\
Evaluation of strategy use & 3.76 & 1.04 \\
Unhelpful (1)-helpful (5) & 3.81 & 1.08 \\
Ineffective (1)-effective (5) & 3.76 & 1.11 \\
Useless (1)-useful (5) & 3.78 & 1.43 \\
Unsuccessful (1)-successful (5) & 3.71 & 1.10 \\
\hline$N=329$ & &
\end{tabular}

TABLE 3 | Situations prone to social media distraction.

\begin{tabular}{lcr}
\hline & M & SD \\
\hline While watching a movie/series & 2.85 & 1.30 \\
When I do not want to start with my task after a break & 2.47 & 1.24 \\
When I want to delay the start of a task & 2.22 & 1.21 \\
When I have to do an unpleasant task & 2.16 & 1.19 \\
When I would have other, more important tasks to do & 2.12 & 1.13 \\
While studying/working & 2.06 & 1.13 \\
When talking to family/friends/others & 1.86 & 1.02 \\
When I am eating with others & 1.64 & 0.92 \\
When I actively participate in traffic & 1.57 & 0.93 \\
In a meeting & 1.37 & 0.83
\end{tabular}

$N=329$, English translation of the original German items used in this study, original items are in our OSF repository. We gave a brief description of distraction by social media: it was described as referring to situations in which people, while performing a task, are distracted by social media, either internally or externally. Introduction to these items: "When you are in one of the following situations, how often do you get distracted?".

returning back to a task, or when they wanted to delay the start of a task.

Strategies that were used to reduce distractions are presented in Table 4. The most common strategies were silencing the devices, leaving the devices somewhere else, or deactivating notifications. Overall, participants evaluated their use of strategies to limit social media distractions as moderately effective $(M=3.76, \mathrm{SD}=1.04)$.

\section{Reasons for Social Media Distraction}

Moreover, we investigated the reasons for social media distraction (RQ2). Table 5 shows the descriptive statistics of the items measuring reasons for distraction. To find underlying types of reasons, we conducted an exploratory factor analysis (EFA). EFA is used when the underlying factor structure is not known, as it was the case in our study. We calculated the
TABLE 4 | Strategies used to reduce distractions by social media.

\begin{tabular}{|c|c|c|}
\hline & $M$ & SD \\
\hline ... silence my devices & 3.51 & 1.45 \\
\hline ... leave my device at a different location (e.g., other room, at home) & 2.58 & 1.36 \\
\hline ... deactivate notifications & 2.55 & 1.48 \\
\hline ... place the device out of reach & 2.49 & 1.35 \\
\hline ... turn my device around so that I cannot see any notifications & 2.41 & 1.36 \\
\hline ... turn off my device & 2.33 & 1.36 \\
\hline ... deactivate the Internet connection & 2.25 & 1.35 \\
\hline ... log off my social media accounts & 2.22 & 1.41 \\
\hline ... activate flight mode & 2.10 & 1.30 \\
\hline ... treat myself for successfully avoiding social media & 1.64 & 1.03 \\
\hline ... use apps/plug ins to control my social media use & 1.59 & 1.06 \\
\hline ... delete my social media apps (temporarily) & 1.57 & 1.02 \\
\hline ... lock my device away & 1.55 & 1.00 \\
\hline ... give my device to another person (e.g., spouse) & 1.50 & 0.96 \\
\hline ... delete my social media accounts & 1.44 & 0.91 \\
\hline
\end{tabular}

$N=329$; English translation of the original German items used in this study, original items are in our OSF repository. Introduction to these items: "In order to be less distracted by social media, I..."; Device refers to all that are used for accessing social media.

EFA using oblimin rotation $^{5}$ and principal axis factoring. ${ }^{6}$ With regard to sampling adequacy, the Kaiser-Meyer-Olkin $(\mathrm{KMO})$ measure showed acceptable results: overall, $\mathrm{KMO}=0.94$ and all individual KMO values were $>0.87$. Bartlett's test of sphericity indicated that correlations were sufficiently large: $\chi^{2}$ $(105)=3259.72, p<0.001$. The EFA yielded two factors with eigenvalues greater than 1 and the scree plot indicated that two factors were suitable. Overall, the two factors explained 58\% of the variance.

Table 5 shows the rotated factor loadings of the structure matrix. ${ }^{7}$ Factor loadings were $>0.5$; that is, they were well above the recommended threshold of $>0.4$ (Stevens, 2009; Field, 2013), and they showed no substantial cross-loadings on the other factor (<0.3; Stevens, 2009). Conceptually, Factor 1 relates to task-related reasons for distraction and indicates people being distracted by social media because they try to avoid tasks or do not want to do what they ought to, are bored, or cannot concentrate. Factor 2 relates to social reasons for distraction: people are distracted by social media because they want to feel connected, want to stay in touch, or feel the urge to reply. Hence, reasons for distraction comprised the two factors of social distraction and task-related distraction (each with eight items). The internal consistency of both factors was good (social: $\alpha=0.91$; task-related: $\alpha=0.90)$. As expected, both factors significantly correlated with each other $(r=0.67, p<0.001)$

${ }^{5} \mathrm{We}$ used an oblique rotation, since this is recommended when a correlation between factors is expected (Finch and French, 2015, p. 14) and considered reasonable (Stevens, 2009, p. 331). We assumed that the factors represent faces of distraction rather than clearly distinguishable dimensions and, hence, expected them to be correlated.

${ }^{6}$ We used in R the "fa" function from "psych" package.

${ }^{7} \mathrm{We}$ excluded the item "I have nothing to do anyways" which had emerged from the interviews because we considered it to be conceptually different from distraction. 
TABLE 5 | Exploratory factor analysis of reasons for distraction.

\begin{tabular}{|c|c|c|c|c|}
\hline & \multirow[t]{2}{*}{$M$} & \multirow[t]{2}{*}{ SD } & \multicolumn{2}{|c|}{ Factor loading } \\
\hline & & & 1 & 2 \\
\hline \multicolumn{5}{|l|}{ Factor 1: social reasons } \\
\hline $\begin{array}{l}\text {... It is important to me to directly } \\
\text { reply }\end{array}$ & 2.18 & 1.21 & 0.86 & -0.14 \\
\hline ... I always directly reply & 2.21 & 1.23 & 0.77 & -0.06 \\
\hline ... I always want to be up to date & 2.42 & 1.28 & 0.77 & 0.07 \\
\hline $\begin{array}{l}\ldots \text { I want to know what is } \\
\text { happening }\end{array}$ & 2.80 & 1.28 & 0.74 & 0.09 \\
\hline $\begin{array}{l}\ldots \text { I I want to keep up with what } \\
\text { others are doing }\end{array}$ & 2.51 & 1.23 & 0.73 & 0.09 \\
\hline $\begin{array}{l}\text {... I want to know what others are } \\
\text { writing/posting/liking/sharing }\end{array}$ & 2.72 & 1.30 & 0.69 & 0.06 \\
\hline ... My friends expect me to react & 2.46 & 1.23 & 0.68 & 0.02 \\
\hline $\begin{array}{l}\text {... I want to stay in touch with } \\
\text { friends }\end{array}$ & 3.13 & 1.27 & 0.65 & 0.09 \\
\hline \multicolumn{5}{|l|}{ Factor 2: task-related reasons } \\
\hline $\begin{array}{l}\ldots \text { I am not interested in pursuing } \\
\text { my tasks }\end{array}$ & 2.45 & 1.29 & -0.10 & 0.93 \\
\hline $\begin{array}{l}\text {... I want to escape an (unpleasant) } \\
\text { situation }\end{array}$ & 2.21 & 1.22 & -0.03 & 0.87 \\
\hline ... I want to get distracted & 2.52 & 1.31 & 0.07 & 0.71 \\
\hline ... I cannot concentrate & 2.53 & 1.23 & 0.10 & 0.67 \\
\hline ... I am bored & 2.98 & 1.34 & 0.09 & 0.63 \\
\hline $\begin{array}{l}\text {... I got interrupted by a notification } \\
\text { while pursuing a task }\end{array}$ & 2.34 & 1.22 & 0.21 & 0.58 \\
\hline $\begin{array}{l}\text {... I am seeking entertainment and } \\
\text { fun }\end{array}$ & 2.86 & 1.28 & 0.29 & 0.51 \\
\hline Eigenvalue & & & 4.82 & 3.91 \\
\hline Explained Variance & & & $32 \%$ & $26 \%$ \\
\hline
\end{tabular}

which indicates that the two types of distractions are not independent from each other, but rather depict different facets of distraction. Overall, the scale assesses how strongly people are distracted by social media due to social and task-related reasons.

\section{Individual Differences as Predictors of Social Media Distraction}

We investigated which individual differences predicted users' social media distraction (RQ3). Table 6 shows that all trait variables correlated with social distraction and task-related distraction. In order to analyze which of the traits are most important for each type of distraction, we calculated two hierarchical regressions, one with social distraction and one with task-related distraction as dependent variable.

In step 1 of the hierarchical regressions, we entered the general trait variables basic motives (achievement, power, affiliation, intimacy), self-control, and impulsivity as predictors. For social distraction (Table 7), these predictors accounted for about $20 \%$ of variance; power, affiliation, and self-control emerged as significant predictors. The stronger the power $(\beta=0.18)$ and affiliation $(\beta=0.21)$ motive, the higher was social distraction.
Higher self-control $(\beta=-0.25)$ reduced social distraction. For task-related distraction (Table 8), the model accounted for $25 \%$ of variance; achievement, self-control, and impulsivity emerged as significant predictors. The higher the achievement motive $(\beta=0.14)$ and impulsivity $(\beta=0.16)$, the higher was task-related distraction. Again, higher self-control $(\beta=-0.32)$ was associated with reduced task-related distraction.

In step 2, we included the social media-specific variables problematic social media use (craving and loss of control) and FoMO (online and offline) as predictors. For social distraction (Table 7), these additional predictors increased the explained variance significantly to $49 \%$. While affiliation was still a significant predictor $(\beta=0.11)$, power and self-control were no longer significant. In addition, online FoMO emerged as the strongest predictor of social distraction $(\beta=0.64)$. For taskrelated distraction (Table 8 ), the additional social media-specific predictors increased the explained variance significantly to $45 \%$. None of the general trait variables remained significant; instead, all social media-specific variables significantly predicted taskrelated distraction. While loss of control $(\beta=0.41)$, offline FoMO $(\beta=0.13)$, and online FoMO $(\beta=0.24)$ were associated with higher task-related distraction, craving $(\beta=-0.17)$ was associated with lower task-related distraction.

\section{DISCUSSION}

This research examined distraction by social media, and, more specifically, when, and why people are distracted, and what they do to reduce their distraction. We examined this with a larger German sample that is diverse in terms of demographic characteristics such as age, educational background, and occupation (see Table 1) and by investigating social media distraction in general, rather than focusing only on one social media platform. We identified typical distraction situations (e.g., when pursuing a task) and typical strategies users employ to be less distracted (e.g., silencing notifications). By focusing on reasons for distraction, we identified two types of social media distraction: social distraction and task-related distraction. These types of distraction differed in their association with individual differences in basic motives, self-regulatory abilities, problematic social media use, and FoMO.

\section{Situations of and Strategies Against Social Media Distraction}

According to $U \& G$, the environment influences media use and effects (Ruggiero, 2000; Rubin, 2002). Against this backdrop, we identified typical situations in which participants were distracted by social media (RQ1). This extends previous research, which has focused on social media distraction only in one particular context (e.g., studying; Chen and Yan, 2016). An interesting finding is that social media distraction occurs not only in non-interactive situations (e.g., when working on a task or watching a movie), but also when users are interacting with other people (e.g., when talking to others or when in a meeting). Although participants indicated that distraction in interactive situations is less frequent than in non-interactive situations, previous research has revealed that 
TABLE 6 | Descriptive statistics and correlations for reasons for distraction and traits.

\begin{tabular}{|c|c|c|c|c|c|c|c|c|c|c|c|c|c|}
\hline Variable & $M$ & SD & 1 & 2 & 3 & 4 & 5 & 6 & 7 & 8 & 9 & 10 & 11 \\
\hline 1. Self-control & 3.28 & 0.67 & - & & & & & & & & & & \\
\hline 2. Impulsivity & 2.11 & 0.43 & $-0.61^{\star \star \star}$ & - & & & & & & & & & \\
\hline \multicolumn{14}{|c|}{ Fear of missing out } \\
\hline 3. Offline & 2.02 & 0.94 & $-0.46^{\star \star \star}$ & $0.30^{\star \star \star}$ & - & & & & & & & & \\
\hline 4. Online & 2.00 & 0.88 & $-0.33^{\star \star \star}$ & $0.29^{\star \star \star}$ & $0.70^{\star \star \star}$ & - & & & & & & & \\
\hline \multicolumn{14}{|c|}{ Problematic social media use } \\
\hline 5. Loss of control & 2.22 & 0.87 & $-0.43^{\star \star \star}$ & $0.36^{\star \star \star}$ & $0.54^{\star \star \star}$ & $0.63^{\star \star \star}$ & - & & & & & & \\
\hline 6. Craving & 1.85 & 0.85 & $-0.36^{\star \star \star}$ & $0.37^{\star \star \star}$ & $0.56^{\star \star \star}$ & $0.63^{\star \star \star}$ & $0.83^{\star \star \star}$ & - & & & & & \\
\hline \multicolumn{14}{|l|}{ Basic motives } \\
\hline 7. Achievement & 3.12 & 0.90 & 0.10 & -0.10 & $0.21^{\star \star \star}$ & $0.29^{\star \star \star}$ & $0.19^{\star \star \star}$ & $0.18^{\star \star \star}$ & - & & & & \\
\hline 8. Power & 2.51 & 0.90 & 0.01 & 0.00 & $0.34^{\star \star \star}$ & $0.40^{\star \star \star}$ & $0.28^{\star \star \star}$ & $0.33^{\star \star \star}$ & $0.60^{\star \star \star}$ & - & & & \\
\hline 9. Affiliation & 3.09 & 0.78 & 0.09 & -0.10 & $0.16^{\star \star}$ & $0.22^{\star \star \star}$ & 0.05 & 0.01 & $0.45^{\star \star \star}$ & $0.27^{\star \star \star}$ & - & & \\
\hline 10. Intimacy & 3.60 & 0.78 & -0.03 & $-0.11^{\star}$ & 0.08 & 0.04 & 0.06 & -0.02 & $0.34^{\star \star \star}$ & 0.07 & $0.47^{\star \star \star}$ & - & \\
\hline \multicolumn{14}{|c|}{ Reasons for distraction } \\
\hline 11. Social & 2.55 & 0.99 & $-0.26^{\star \star \star}$ & $0.18^{\star \star \star}$ & $0.47^{\star \star \star}$ & $0.68^{\star \star \star}$ & $0.47^{\star \star \star}$ & $0.45^{\star \star \star}$ & $0.24^{\star \star \star}$ & $0.27^{\star \star \star}$ & $0.26^{\star \star \star}$ & $0.14^{\star}$ & - \\
\hline 12. Task-related & 2.21 & 0.89 & $-0.40^{\star \star \star}$ & $0.33^{\star \star \star}$ & $0.52^{\star \star \star}$ & $0.57^{\star \star \star}$ & $0.60^{\star \star \star}$ & $0.49^{\star \star \star}$ & $0.22^{\star \star \star}$ & $0.21^{\star \star \star}$ & $0.18^{\star \star \star}$ & $0.15^{\star \star}$ & $0.67^{\star \star \star}$ \\
\hline
\end{tabular}

$N=329$. Pearson's r correlation coefficient; ${ }^{*} p<0.05,{ }^{* *} p<0.01,{ }^{* * *} p<0.001$.

TABLE 7 | Hierarchical regression examining the effect of traits on social distraction.

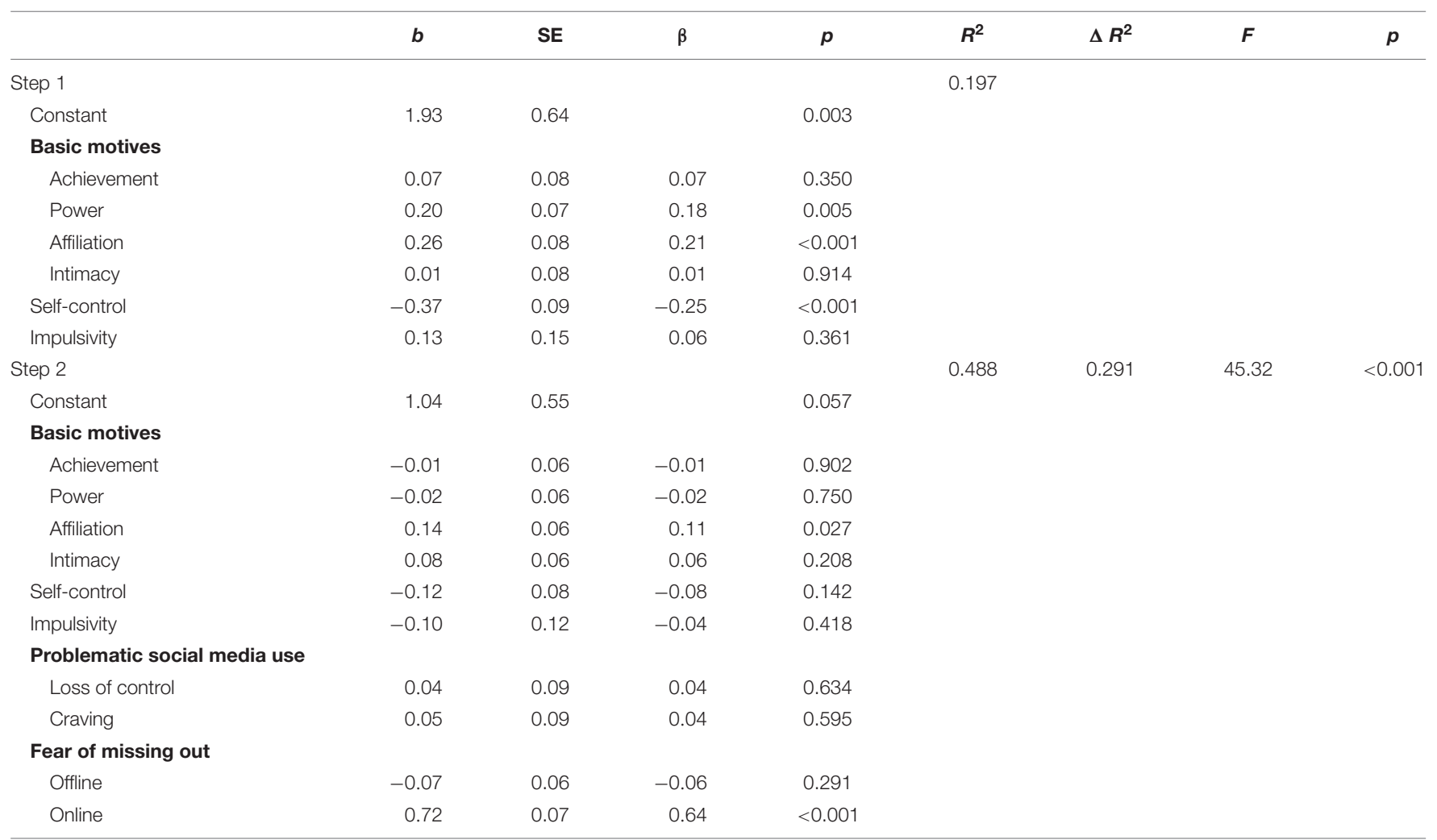

$N=329$.

distraction in interactive situations may have strong negative effects, for instance, during social interaction it can negatively affect well-being (Xu et al., 2016) or relationship formation (Przybylski and Weinstein, 2013). Previous research has also argued that social media is used to escape unpleasant situations (Reinecke et al., 2018).
In addition, our study identified strategies that people use to reduce social media distraction. The most popular strategies, such as silencing the device, deactivating notifications, or placing the device out of sight, address external distractions. These strategies tackle the problem that push notifications demand users' attention (Hofmann et al., 2017). Previous research 
TABLE 8 | Hierarchical regression examining the effect of traits on task-related distraction.

\begin{tabular}{|c|c|c|c|c|c|c|c|c|}
\hline & $b$ & SE & $\beta$ & $p$ & $R^{2}$ & $\Delta R^{2}$ & $F$ & $p$ \\
\hline Step 1 & & & & & 0.252 & & & \\
\hline Constant & 1.95 & 0.62 & & 0.002 & & & & \\
\hline \multicolumn{9}{|l|}{ Basic motives } \\
\hline Achievement & 0.15 & 0.07 & 0.14 & 0.036 & & & & \\
\hline Power & 0.11 & 0.07 & 0.10 & 0.116 & & & & \\
\hline Affiliation & 0.14 & 0.07 & 0.11 & 0.059 & & & & \\
\hline Intimacy & 0.07 & 0.07 & 0.05 & 0.368 & & & & \\
\hline Self-control & -0.47 & 0.09 & -0.32 & $<0.001$ & & & & \\
\hline Impulsivity & 0.36 & 0.14 & 0.16 & 0.012 & & & & \\
\hline Step 2 & & & & & 0.452 & 0.200 & 28.91 & $<0.001$ \\
\hline Constant & 0.49 & 0.56 & & 0.388 & & & & \\
\hline \multicolumn{9}{|l|}{ Basic motives } \\
\hline Achievement & 0.09 & 0.06 & 0.08 & 0.158 & & & & \\
\hline Power & -0.06 & 0.06 & -0.06 & 0.312 & & & & \\
\hline Affiliation & 0.07 & 0.07 & 0.05 & 0.309 & & & & \\
\hline Intimacy & 0.08 & 0.06 & 0.06 & 0.227 & & & & \\
\hline Self-control & -0.13 & 0.09 & -0.09 & 0.136 & & & & \\
\hline Impulsivity & 0.20 & 0.12 & 0.09 & 0.107 & & & & \\
\hline \multicolumn{9}{|c|}{ Problematic social media use } \\
\hline Loss of control & 0.47 & 0.09 & 0.41 & $<0.001$ & & & & \\
\hline Craving & -0.19 & 0.09 & -0.17 & 0.039 & & & & \\
\hline \multicolumn{9}{|c|}{ Fear of missing out } \\
\hline Offline & 0.14 & 0.07 & 0.13 & 0.038 & & & & \\
\hline Online & 0.27 & 0.08 & 0.24 & $<0.001$ & & & & \\
\hline
\end{tabular}

$N=329$.

suggests that such strategies are indeed successful. Simply being able to see the device is already distracting (Johannes et al., 2018b). Along similar lines, Aagaard (2015) found that students close their laptops strategically to reduce in-class distractions. However, strategies reducing external distractors (e.g., silencing notifications, relocating the device) may not suffice in reducing distractions (Pielot et al., 2014), because these strategies still allow easy access to social media, rely on internal control capabilities, and people may still be distracted internally (e.g., thinking about unread messages or likes). Participants also reported more drastic strategies, such as deleting accounts or apps. Obviously, our findings suggest that more drastic (and probably more effective) strategies are less likely to be adopted.

\section{Distraction Due to Social and Task-Related Reasons}

By focusing on users' underlying reasons (RQ2), we identified two types of social media distraction: social distraction and task-related distraction. Social distraction refers to an increased susceptibility to social media distractions because of striving for social connection and fulfilling others' expectations. This corresponds to previous research arguing that social cravings motivate multitasking (Wang et al., 2012), problematic smartphone use (Seo et al., 2015), or distracting behavior (Clayson and Haley, 2013; Bayer et al., 2016), because social media use is socially rewarding (Bayer et al., 2016). Other studies have found that communicating with and being concerned about others are dominant reasons for in-class social media use
(Clayson and Haley, 2013) and that social pressure is a main reason for quickly reacting to notifications (Pielot et al., 2014).

Task-related distraction, on the other hand, refers to an increased susceptibility to social media distractions in order to avoid unpleasant tasks, or to make uncomfortable situations more pleasant. This finding aligns with U\&G research, which has often highlighted that people use media for entertainment or to avoid unpleasant thoughts (Ruggiero, 2000). Additionally, previous work has argued that people use (social) media to regulate their mood (Hofmann et al., 2017; Reinecke et al., 2018) or to make tasks more entertaining (Wang and Tchernev, 2012). For instance, previous research has suggested that students use social media during classes to procrastinate (Rozgonjuk et al., 2018) or out of boredom (Clayson and Haley, 2013). To summarize, the identified types of distraction indicate which possible gratifications make people more susceptible to social media distraction. From a U\&G perspective, an investigation of these underlying reasons for social media distraction is important because, as Rubin (2002) argued, the motivations for media use influence the effects of media on its users.

\section{Individual Differences and Distraction}

Our research aim was to examine whether individual differences in general and social media-specific traits in particular explain social media distraction (RQ3). We investigated various predictors that differ substantially for social versus taskrelated distraction. This underlines that social and task-related distraction are indeed different types of distraction because 
they are driven by different psychological processes. Thus, our results correspond to previous research on U\&G stating that individual differences influence media use (Rubin, 2002; Sherry and Boyan, 2008).

When considering the general traits (hierarchical regression step 1), both types of distraction were predicted by lower selfcontrol; in the case of task-related distraction, additionally by lower impulsivity. Importantly, social and task-related distraction differed in basic motives. Social distraction was predicted by strong affiliation and power motives. This indicates that social media distraction might be driven not only by the striving to connect with others but also by the exertion of power over others. For instance, previous research has argued that feeling socially excluded, in particular, makes users turn to social media (David and Roberts, 2017), indicating that a susceptibility to social media would be motivated by the need for social connection. Task-related distraction, by contrast, was predicted by a strong achievement motive. At first, this seems contrary to previous research arguing that people turn to media when faced with tasks that are "demanding, complex, unpleasant, boring or anxietyinducing" (Reinecke et al., 2018, p. 864), and that students are susceptible to distractions in a difficult lecture (Aagaard, 2015). However, it fits well to research that has linked perfectionism as well as low self-control to procrastination (Ferrari, 1992; Przepiórka et al., 2019). Overall, the findings on the relationship between social media distraction and general traits provide two major insights. First, lower self-regulatory abilities contribute to social media distraction. This is in line with previous research that has conceptualized problematic social media use as a problem with self-control (Wegmann et al., 2015). In addition, it corresponds to the literature on mind wandering, identifying internal distractions as failed attentional control (McVay and Kane, 2010). Second, the findings show that, in addition to self-regulation, users' motivational dispositions have additional explanatory power for social media distraction. This suggests that taking users' motives into account, as suggested by U\&G (Rubin, 2002), provides a more complete picture of social media distraction than the self-control perspective alone.

When including social media-specific variables (hierarchical regression step 2), the pattern of predictors changes, but substantial differences between social distraction and task-related distraction persist. For social distraction, the affiliation motive is still a significant predictor, but FoMO emerged as the most important predictor. This result is not surprising since FoMO refers to the striving to stay socially connected (Przybylski et al., 2013) and is related to higher social media use (Przybylski et al., 2013; Hunt et al., 2018). For task-related distraction, problematic social media use in the form of loss of control and craving are significant predictors. These refer to more social mediaspecific aspects of self-control and thus seem to replace the more general predictors-namely, self-control and impulsivityidentified in step 1. This corresponds to previous research showing that problematic social media use is associated with lower productivity (Duke and Montag, 2017). In addition, FoMO contributes to task-related distraction, which suggests that users neglect their tasks in favor of not missing out on things online as well as offline. Taken together, the findings show that users with low self-regulatory abilities and high FoMO are more prone to task-related distraction. For social distraction, FoMO is the most important predictor and users do not need to have low self-control to be susceptible to social media distractions.

\section{Limitations}

Our study has certain limitations, which, at the same time, point to opportunities for future research. First, this study focused on users' perception of distraction and thus is based on participants' self-reports to capture their perception. In order to expand this perspective, future research should relate these subjective perceptions to more objective measures of social media distraction. For instance, use eye-tracking could be used to examine whether self-reported social media distraction goes along with higher visual distractibility by social media cues (see Serfas et al., 2016).

Second, we identified individuals' use of strategies against distraction, but the effectiveness of these strategies remains unclear. By exploring users' popular strategies, we tackled the call to investigate strategies that are realistically used in everyday situations (Chen and Yan, 2016). The next step should be to empirically test which of these strategies really help in reducing distractions. Furthermore, the popular strategies found here focus on reducing external distractions. Thus, future research could investigate strategies against internal distractions because previous research has indicated that reducing internal distractions might require different strategies (Rosen et al., 2013).

Third, we chose an exploratory approach. Hence, it is up to future research to explore causal relations. In our study, we identified the two reasons for distraction, but it is thus far unclear how these affect the susceptibility to distractions either in particular situations or in relation to employing different strategies. This requires experimental research. Finally, our sample is demographically diverse, but limited to participants from Germany. Future research is needed to explore social media distraction in different cultural settings.

\section{CONCLUSION}

Social media distractions can easily become a threat to task performance and well-being. For increasing users' agency, future research should develop and test interventions that help users to reduce social media distractions. By identifying reasons for, situations of, and strategies against social media distraction, the present study provides an important step toward developing such interventions.

\section{DATA AVAILABILITY STATEMENT}

The datasets presented in this study can be found in online repositories. The names of the repository and accession number can be found below: OSF: https://osf.io/5pvj6/.

\section{ETHICS STATEMENT}

The studies involving human participants were reviewed and approved by the Ethics Committee of the Department of 
Computer Science and Applied Cognitive Science, University of Duisburg-Essen, Duisburg, Germany. The participants provided their informed consent to participate in this study.

\section{AUTHOR CONTRIBUTIONS}

$\mathrm{CK}$ and $\mathrm{OB}$ designed the study. CK organized data collection, performed the statistical analysis, and wrote the first draft of the manuscript. CK and $\mathrm{OB}$ revised the manuscript and approved the submitted version.

\section{REFERENCES}

Aagaard, J. (2015). Drawn to distraction: a qualitative study of off-task use of educational technology. Comput. Educ. 87, 90-97. doi: 10.1016/j.compedu. 2015.03.010

Baumeister, R. F., and Heatherton, T. F. (1996). Self-Regulation failure: an overview. Psychol. Inq. 7, 1-15.

Bayer, J. B., Campbell, S. W., and Ling, R. (2016). Connection cues: activating the norms and habits of social connectedness. Commun. Theory 26, 128-149. doi: $10.1111 /$ comt.12090

Berger, S., Wyss, A. M., and Knoch, D. (2018). Low self-control capacity is associated with immediate responses to smartphone signals. Comput. Hum. Behav. 86, 45-51. doi: 10.1016/j.chb.2018.04.031

Bertrams, A., and Dickhäuser, O. (2009). Messung dispositioneller selbstkontrollkapazität: eine deutsche adaptation der kurzform der self-control scale (SCS-KD) [Measuring dispositional self-control capacity: a german adaptation of the short self-control scale (SCS-K-D)]. Diagnostica 55, 2-10. doi: 10.1026/00121924.55.1.2

Brooks, S. (2015). Does personal social media usage affect efficiency and wellbeing? Comput. Hum. Behav. 46, 26-37. doi: 10.1016/j.chb.2014.12.053

Brooks, S., and Califf, C. (2017). Social media-induced technostress: its impact on the job performance of IT professionals and the moderating role of job characteristics. Comput. Netw. 114, 143-153. doi: 10.1016/j.comnet.2016.08. 020

Carrier, L. M., Rosen, L. D., Cheever, N. A., and Lim, A. F. (2015). Causes, effects, and practicalities of everyday multitasking. Dev. Rev. 35, 64-78. doi: 10.1016/j. dr.2014.12.005

Chen, Q., and Yan, Z. (2016). Does multitasking with mobile phones affect learning? A review. Comput. Hum. Behav. 54, 34-42. doi: 10.1016/j.chb.2015. 07.047

Clapp, W. C., and Gazzaley, A. (2012). Distinct mechanisms for the impact of distraction and interruption on working memory in aging. Neurobiol. Aging 33, 134-148. doi: 10.1016/j.neurobiolaging.2010.01.012

Clayson, D. E., and Haley, D. A. (2013). An introduction to multitasking and texting:prevalence and impact on grades and gpa in marketing classes. J. Mark. Educ. 35, 26-40. doi: 10.1177/0273475312467339

David, M. E., and Roberts, J. A. (2017). Phubbed and alone: phone snubbing, social exclusion, and attachment to social media. J. Assoc. Cons. Res. 2, 155-163. doi: $10.1086 / 690940$

Du, J., van Koningsbruggen, G. M., and Kerkhof, P. (2018). A brief measure of social media self-control failure. Comput. Hum. Behav. 84, 68-75. doi: 10.1016/ j.chb.2018.02.002

Duke, E., and Montag, C. (2017). Smartphone addiction, daily interruptions and self-reported productivity. Addict. Behav. Rep. 6, 90-95. doi: 10.1016/j.abrep. 2017.07.002

Emmons, R. (1997). "Motives and life goals," in Handbook of Personality Psychology, eds R. Hogan, J. Johnson, and S. Briggs (San Diego, CA: Academic Press), 485-512.

Ferrari, J. R. (1992). Procrastinators and perfect behavior: an exploratory factor analysis of self-presentation, self-awareness, and self-handicapping components. J. Res. Pers. 26, 75-84. doi: 10.1016/0092-6566(92)90060-H

\section{FUNDING}

This work was supported by the German Research Foundation (DFG), Research Training Group "User-Centred Social Media” under Grant GRK 2167.

\section{ACKNOWLEDGMENTS}

We thank Lynn Brinkmann, Katharina Rühl, and Janine Arnold for their assistance with collecting data for the preliminary studies.

Field, A. (2013). Discovering Statistics Using IBM SPSS Statistics: And Sex And Drugs And Rock 'N' Roll. Los Angeles, CA: Sage.

Finch, W. H., and French, B. F. (2015). Latent Variable Modeling with R. New York, NY: Routledge.

Giunchiglia, F., Zeni, M., Gobbi, E., Bignotti, E., and Bison, I. (2018). Mobile social media usage and academic performance. Comput. Hum. Behav. 82, 177-185. doi: 10.1016/j.chb.2017.12.041

Gliklich, E., Guo, R., and Bergmark, R. W. (2016). Texting while driving: a study of 1211 U.S. adults with the distracted driving survey. Prev. Med. Rep. 4, 486-489. doi: 10.1016/j.pmedr.2016.09.003

Hofmann, W., Reinecke, L., and Meier, A. (2017). "Of sweet temptations and bitter aftertaste: self-control as a moderator of media use on well-being," in The Routledge Handbook of Media Use and Well-being: International Perspectives on Theory and Research on Positive Media Effects, eds L. Reinecke and M. B. Oliver (New York, NY: Routledge), 211-222.

Hollis, R. B., and Was, C. A. (2016). Mind wandering, control failures, and social media distractions in online learning. Learn. Instr. 42, 104-112. doi: 10.1016/j. learninstruc.2016.01.007

Hunt, M. G., Marx, R., Lipson, C., and Young, J. (2018). No More FOMO: limiting social media decreases loneliness and depression. J. Soc. Clin. Psychol. 37, 751-768. doi: 10.1521/jscp.2018.37.10.751

Jeong, S., and Hwang, Y. (2016). Media multitasking effects on cognitive vs. attitudinal outcomes: a meta-analysis. Hum. Commun. Res. 42, 599-618. doi: 10.1111/hcre.12089

Johannes, N., Veling, H., Dora, J., Meier, A., Reinecke, L., and Buijzen, M. (2018a). Mind-wandering and mindfulness as mediators of the relationship between online vigilance and well-being. Cyberpsychol. Behav. Soc. Netw. 21, 761-767. doi: $10.1089 /$ cyber.2018.0373

Johannes, N., Veling, H., Verwijmeren, T., and Buijzen, M. (2018b). Hard to resist? The effect of smartphone visibility and notifications on response inhibition. J. Media Psychol. 34, 214-225. doi: 10.1027/1864-1105/a000248

Junco, R., and Cotten, S. R. (2012). No A 4 U: the relationship between multitasking and academic performance. Comput. Educ. 59, 505-514. doi: 10. 1016/j.compedu.2011.12.023

Katz, E., Blumler, J. G., and Gurevitch, M. (1974). Uses and gratifications research. Public Opin. Q. 37, 509-523.

Kushlev, K., Proulx, J., and Dunn, E. W. (2016). “Silence Your Phones': smartphone notifications increase inattention and hyperactivity symptoms," in Proceedings of the 2016 CHI Conference on Human Factors in Computing Systems: Association for Computing Machinery, San Jose, CA, U.S.A. 1011-1020.

Lang, A. (2000). The limited capacity model of mediated message processing. J. Commun. 50, 46-70. doi: 10.1111/j.1460-2466.2000.tb02833.x

McVay, J. C., and Kane, M. J. (2010). "Adrift in the stream of thought: the effects of mind wandering on executive control and working memory capacity," in Handbook of Individual Differences In Cognition: Attention, Memory, And Executive Control, eds A. Gruszka, G. Matthews, and B. Szymura (New York, NY: Springer), 321-334. doi: 10.1007/978-1-4419-1210-7_19

Meule, A., Vögele, C., and Kübler, A. (2011). Psychometrische evaluation der deutschen barratt impulsiveness scale - kurzversion (BIS-15) [Psychometric evaluation of the german barratt impulsiveness scale - short version (BIS-15)]. Diagnostica 57, 126-133. doi: 10.1026/0012-1924/a000042 
Milyavskaya, M., Saffran, M., Hope, N., and Koestner, R. (2018). Fear of missing out: prevalence, dynamics, and consequences of experiencing FOMO. Motivat. Emot. 42, 725-737. doi: 10.1007/s11031-018-9683-5

Papacharissi, Z., and Mendelson, A. (2010). “Toward a new (er) sociability: uses, gratifications and social capital on Facebook," in Media Perspectives For The 21st Century, ed. S. Papathanassopoulos (London: Routledge), 212-230.

Pashler, H. (1994). Dual-task interference in simple tasks: data and theory. Psychol. Bull. 116, 220-244. doi: 10.1037/0033-2909.116.2.220

Pielot, M., Church, K., and de Oliveira, R. (2014). "An in-situ study of mobile phone notifications," in Proceedings of the 16th International Conference On Human-Computer Interaction With Mobile Devices \& Services, (Association for Computing Machinery), Toronto, ON, CA. 233-242.

Przepiórka, A., Błachnio, A., and Siu, N. Y.-F. (2019). The relationships between self-efficacy, self-control, chronotype, procrastination and sleep problems in young adults. Chronobiol. Int. 36, 1025-1035. doi: 10.1080/07420528.2019. 1607370

Przybylski, A. K., and Weinstein, N. (2013). Can you connect with me now? How the presence of mobile communication technology influences faceto-face conversation quality. J. Soc. Pers. Relat. 30, 237-246. doi: 10.1177/ 0265407512453827

Przybylski, A. K., Murayama, K., DeHaan, C. R., and Gladwell, V. (2013). Motivational, emotional, and behavioral correlates of fear of missing out. Comput. Hum. Behav. 29, 1841-1848. doi: 10.1016/j.chb.2013.02.014

Quan-Haase, A., and Young, A. L. (2010). Uses and gratifications of social media: a comparison of Facebook and instant messaging. Bull. Sci. Technol. Soc. 30, 350-361. doi: 10.1177/0270467610380009

Reinecke, L., and Hofmann, W. (2016). Slacking off or winding down? An experience sampling study on the drivers and consequences of media use for recovery versus procrastination. Hum. Commun. Res. 42, 441-461. doi: 10.1111/ hcre. 12082

Reinecke, L., Meier, A., Aufenanger, S., Beutel, M. E., Dreier, M., Quiring, O., et al. (2018). Permanently online and permanently procrastinating? The mediating role of Internet use for the effects of trait procrastination on psychological health and well-being. New Media Soc. 20, 862-880. doi: 10.1177/ 1461444816675437

Roberts, J. A., and David, M. E. (2016). My life has become a major distraction from my cell phone: partner phubbing and relationship satisfaction among romantic partners. Comput. Hum. Behav. 54, 134-141. doi: 10.1016/j.chb.2015.07.058

Rosen, L. D., Carrier, L. M., and Cheever, N. A. (2013). Facebook and texting made me do it: media-induced task-switching while studying. Comput. Hum. Behav. 29, 948-958. doi: 10.1016/j.chb.2012.12.001

Rozgonjuk, D., Kattago, M., and Täht, K. (2018). Social media use in lectures mediates the relationship between procrastination and problematic smartphone use. Comput. Hum. Behav. 89, 191-198. doi: 10.1016/j.chb.2018.08.003

Rubin, A. M. (2002). “The uses-and-gratifications perspective of media effect," in Media Effects: Advances in Theory and Research, eds J. Bryant and D. Zillmann (London: Routledge), 525-548.

Ruggiero, T. E. (2000). Uses and gratifications theory in the 21st century. Mass Commun. Soc. 3, 3-37. doi: 10.1207/s15327825mcs0301_02

Sanbonmatsu, D. M., Strayer, D. L., Medeiros-Ward, N., and Watson, J. M. (2013). Who multi-tasks and why? Multi-tasking ability, perceived multitasking ability, impulsivity, and sensation seeking. PLoS One 8:e54402. doi: 10.1371/journal.pone.0054402

Sariyska, R., Lachmann, B., Cheng, C., Gnisci, A., Sergi, I., Pace, A., et al. (2019). The motivation for facebook use-is it a matter of bonding or control over others? J. Individ. Differ. 40, 26-35. doi: 10.1027/1614-0001/a000273

Schönbrodt, F. D., and Gerstenberg, F. X. R. (2012). An IRT analysis of motive questionnaires: the unified motive scales. J. Res. Pers. 46, 725-742. doi: 10.1016/ j.jrp.2012.08.010

Seo, M., Kim, J.-H., and David, P. (2015). Always connected or always distracted? ADHD symptoms and social assurance explain problematic use of mobile phone and multicommunicating. J. Comput. Med. Commun. 20, 667-681. doi: $10.1111 /$ jcc 4.12140
Serfas, B. G., Büttner, O. B., and Florack, A. (2016). Using implementation intentions in shopping situations: how arousal can help shield consumers against temptation. Appl. Cogn. Psychol. 30, 672-680. doi: 10.1002/acp.3241

Sherry, J. L., and Boyan, A. (2008). "Uses and gratifications," in The International Encyclopedia of Communication, ed. W. Donsbach (Hoboken, NJ: Wiley).

Smock, A. D., Ellison, N. B., Lampe, C., and Wohn, D. Y. (2011). Facebook as a toolkit: a uses and gratification approach to unbundling feature use. Comput. Hum. Behav. 27, 2322-2329. doi: 10.1016/j.chb.2011.07.011

Steel, P. (2007). The nature of procrastination: a meta-analytic and theoretical review of quintessential self-regulatory failure. Psychol. Bull. 133, 65-94. doi: 10.1037/0033-2909.133.1.65

Stevens, J. P. (2009). Applied multivariate statistics for the social sciences, 5th Edn. New York, NY: Routledge.

Tangney, J. P., Baumeister, R. F., and Boone, A. L. (2004). High self-control predicts good adjustment, less pathology, better grades, and interpersonal success. J. Pers. 72, 271-322.

Trash, T. M., Maruskin, L. A., and Martin, C. C. (2012). "Implicit-explicit motive congruence," in The Oxford Handbook of Human Motivation, ed. R. M. Ryan (New York, NY: Oxford University Press), 141-156.

Vorderer, P., Hefner, D., Reinecke, L., and Klimmt, C. (2018). "Permanently online and permanently connected: a new paradigm in communication research?," in Permanently Online, Permanently Connected: Living and Communicating in a POPC World, eds P. Vorderer, D. Hefner, L. Reinecke, and C. Klimmt (New York, NY: Routledge), 3-9.

Wang, Z., and Tchernev, J. M. (2012). The "Myth" of media multitasking: reciprocal dynamics of media multitasking,personal needs, and gratifications. J. Commun. 62, 493-513. doi: 10.1111/j.1460-2466.2012.01641.x

Wang, Z., Tchernev, J. M., and Solloway, T. (2012). A dynamic longitudinal examination of social media use, needs, and gratifications among college students. Comput. Hum. Behav. 28, 1829-1839. doi: 10.1016/j.chb.2012.05.001

Wegmann, E., Oberst, U., Stodt, B., and Brand, M. (2017). Online-specific fear of missing out and internet-use expectancies contribute to symptoms of internetcommunication disorder. Addict. Behav. Rep. 5, 33-42. doi: 10.1016/j.abrep. 2017.04.001

Wegmann, E., Stodt, B., and Brand, M. (2015). Addictive use of social networking sites can be explained by the interaction of internet use expectancies, internet literacy, and psychopathological symptoms. J. Behav. Addict. 4, 155-162. doi: 10.1556/2006.4.2015.021

Whiting, A., and Williams, D. (2013). Why people use social media: a uses and gratifications approach. Q. Market Res. 362-369. doi: 10.1108/QMR-06-20130041

Wilmer, H. H., Sherman, L. E., and Chein, J. M. (2017). Smartphones and cognition: a review of research exploring the links between mobile technology habits and cognitive functioning. Front. Psychol. 8:605. doi: 10.3389/fpsyg.2017.00605

Xu, S., Wang, Z., and David, P. (2016). Media multitasking and well-being of university students. Comput. Hum. Behav. 55, 242-250.

Conflict of Interest: The authors declare that the research was conducted in the absence of any commercial or financial relationships that could be construed as a potential conflict of interest.

Publisher's Note: All claims expressed in this article are solely those of the authors and do not necessarily represent those of their affiliated organizations, or those of the publisher, the editors and the reviewers. Any product that may be evaluated in this article, or claim that may be made by its manufacturer, is not guaranteed or endorsed by the publisher.

Copyright (c) 2021 Koessmeier and Büttner. This is an open-access article distributed under the terms of the Creative Commons Attribution License (CC BY). The use, distribution or reproduction in other forums is permitted, provided the original author(s) and the copyright owner(s) are credited and that the original publication in this journal is cited, in accordance with accepted academic practice. No use, distribution or reproduction is permitted which does not comply with these terms. 